\title{
Corpus
}

\section{Un museo a cielo abierto en el piedemonte tucumano}

\section{Diego Nemec and Santiago Garaño}

\section{(2) OpenEdition \\ 1 Journals}

\section{Electronic version}

URL: http://journals.openedition.org/corpusarchivos/3438

DOI: 10.4000/corpusarchivos.3438

ISSN: 1853-8037

\section{Publisher}

Diego Escolar

\section{Electronic reference}

Diego Nemec y Santiago Garaño, « Un museo a cielo abierto en el piedemonte tucumano », Corpus [En línea], Vol. 10, №. 1 | 2020, Publicado el 28 junio 2020, consultado el 02 julio 2020. URL : http:// journals.openedition.org/corpusarchivos/3438; DOI : https://doi.org/10.4000/corpusarchivos.3438

This text was automatically generated on 2 July 2020.

Licencia Creative Commons: Atribución-NoComercial 2.5 Argentina (CC BY-NC 2.5 AR) 


\title{
Un museo a cielo abierto en el piedemonte tucumano
}

\author{
Diego Nemec and Santiago Garaño
}

1 Este texto no se refiere a un tradicional museo en donde una de las Fuerzas Armadas escenifica un relato oficial y público sobre su historia, instalado en un edificio propio y visitado principalmente por un público externo a la institución. En cambio, trata sobre cuatro pueblos rurales fundados por el Ejército argentino durante los inicios de la última dictadura en el sudoeste tucumano, bautizados con nombres de uniformados “caídos" durante el Operativo Independencia y construidos para reubicar a cientos de pobladores rurales que vivían en el piedemonte de las Sierras del Aconquija. A los fines de este debate los consideraremos una especie de museo a cielo abierto que los militares montaron para producir una memoria - oficial y temprana- de la primera etapa del Operativo Independencia destinada a un público que incluyó, de manera privilegiada, a la población local. ${ }^{1}$

\section{Los cuatro pueblos del sudoeste tucumano}

Los pueblos Teniente Berdina, Capitán Cáceres, Sargento Moya y Soldado Maldonado fueron construidos entre 1976 y 1977 en el epicentro de la "zona de operaciones" montada durante el Operativo Independencia en el sudoeste tucumano. Se fundaron en parajes rurales ubicados en el piedemonte de las Sierras del Aconquija durante la gobernación de facto del general Antonio Domingo Bussi y allí fueron trasladados centenares de pobladores - la mayor parte de ellos peones rurales junto a sus familiasque hasta ese momento vivían dispersos en las fincas azucareras de la zona (Imagen № 1). 
Los asentamientos se edificaron en el marco de las acciones castrenses llevadas a cabo durante el Operativo Independencia para terminar con una larga tradición de conflictividad política y sindical que presentaba la provincia. Esa conflictividad se había hecho fuerte durante el año 1974 con la circulación de un pequeño foco guerrillero organizado por el Ejército Revolucionario del Pueblo en el sudoeste tucumano - la llamada "Compañía de Monte Ramón Rosa Jiménez"- y con el protagonismo que en el conjunto de esa zona tuvieron los trabajadores azucareros durante la espectacular huelga llevada a cabo en septiembre de 1974 por la Federación Obrera Tucumana de la Industria del Azúcar (FOTIA) (Taire, 2008). Contra los actores claves de esa conflictividad (pero no solamente contra ellos) se desplegó aquel operativo que los militares iniciaron en febrero de 1975 y que Bussi comandó desde diciembre de ese año.

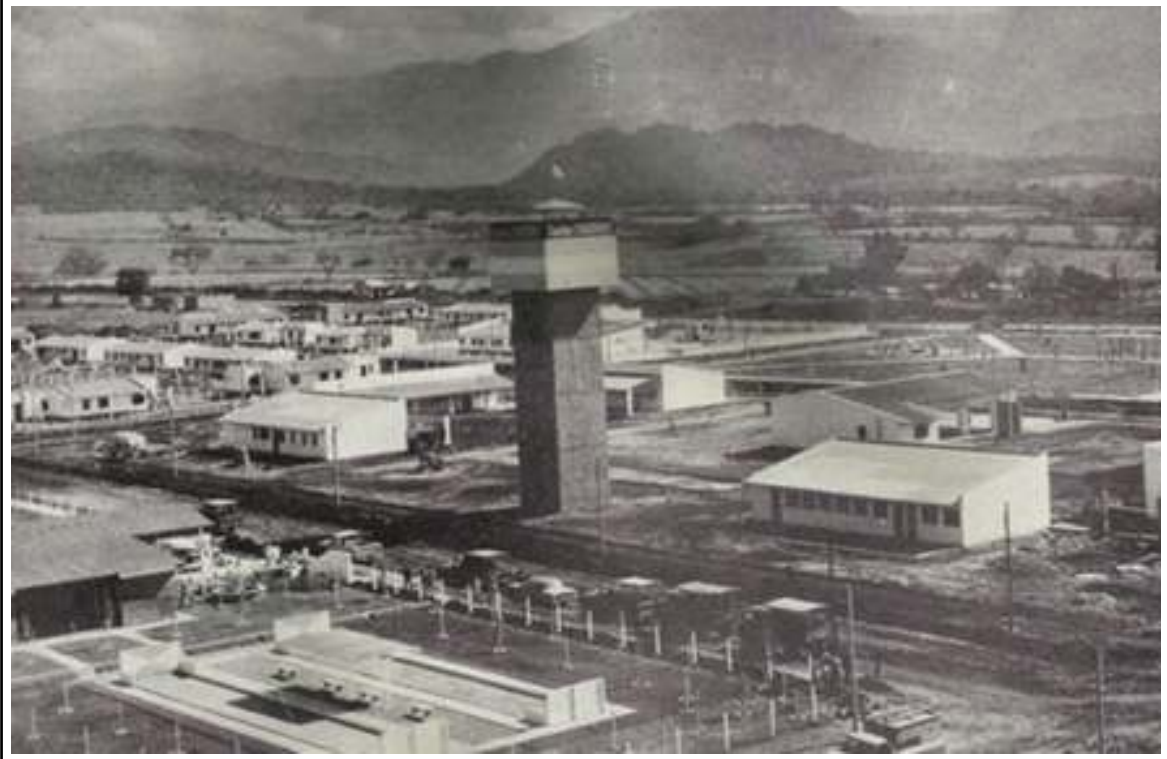

Imagen $N^{0} 1$. Vista de Capitán Cáceres en el piedemonte tucumano.

(Fuente: Gobierno de la provincia de Tucumán, 1977)

3 Si bien en el sudoeste tucumano se produjeron algunos "enfrentamientos" entre las tropas del Ejército y los guerrilleros, la represión fue llevada a cabo primordialmente a través de prácticas ilegales que configuraron un escenario de violaciones a los derechos humanos que luego se aplicaron en el resto del país (Pucci, 2009). Dirigentes sindicales y partidarios, trabajadores azucareros, guerrilleros y estudiantes fueron algunas de las víctimas de un método represivo que tuvo su eje principal en el uso planificado y sistemático del secuestro, la tortura, el asesinato y la desaparición de sus cuerpos, así como en la organización de los primeros centros clandestinos de detención en los que se produjeron estos delitos (Comisión Bicameral investigadora de las violaciones de los Derechos Humanos, 1991).

4 Cuando los pueblos empezaron a construirse, en agosto de 1976, la conflictividad política y sindical - que había puesto en vilo la autoridad de las clases y actores que dominaban la producción azucarera en la zona- ya había sido arrasada a fuerza de sangre y de terror debido a la actuación castrense. La construcción de los asentamientos tuvo, por esa razón, una finalidad preventiva: controlar a la población reubicada para desvincularla de aquella tradición de conflictividad y evitar que se repitiera una coyuntura similar a la de 1974. 
5 Además de quedar atravesados por las tareas de control poblacional y la violencia represiva, los pueblos fueron lugares en donde el Ejército desplegó estrategias destinadas a lograr el apoyo de la población y la producción de sujetos y subjetividades afines al proyecto autoritario de los militares. En ese sentido, su construcción estuvo atravesada por la "acción cívica" y la "acción psicológica" que, junto a la represiva, eran los elementos programáticos de la doctrina contrainsurgente que los uniformados venían aplicando desde los inicios del Operativo Independencia en Tucumán (Franco, 2012). Estas estrategias incluían tareas de desarrollo social orientadas a mejorar las condiciones de vida y acciones de propaganda, ambas destinadas a alcanzar el consenso y la adhesión de la población. En este marco, los militares construyeron los cuatro asentamientos como vehículos de memoria (Jelin, 2002) para producir un relato justificatorio y legitimador de las acciones llevadas a cabo durante la primera etapa del Operativo Independencia, cuestión específica que abordaremos a continuación. ${ }^{2}$

\section{Una memoria estatal de la "guerra antisubversiva"}

6 Los pueblos fundados en el sudoeste tucumano fueron usados por los militares para producir y difundir una memoria estatal temprana de la primera etapa del Operativo Independencia centrada en la figura de la "guerra contra la subversión". Al estar emplazados en el epicentro de la "zona de operaciones" eran escenarios ideales para sobredimensionar los relatos castrenses de los "enfrentamientos" contra los "subversivos", poniendo en primer plano los homenajes a los "caídos". Las representaciones de la "guerra" les sirvieron a los uniformados para legitimar y justificar su accionar en la zona, silenciando las formas represivas ilegales y legitimando la vigilancia sobre la población reubicada.

7 Este uso de las figuraciones bélicas con fines justificatorios y legitimadores fue una moneda corriente en la Argentina de aquellos años. Los cuatro asentamientos, al estar ubicados en un territorio que los militares consideraban emblemático de la "lucha contra la subversión", se construyeron como lugares en los que esos relatos podían montarse sobre los discursos nacionales preexistentes, reforzándolos y ejemplificándolos. En los párrafos que siguen daremos cuenta de algunas marcas materiales, prácticas y discursos que los uniformados produjeron durante el proceso constructivo de estos pueblos con el fin de representar lo sucedido durante el Operativo Independencia en clave bélica.

8 Comenzaremos con uno de los rasgos arquitectónicos más llamativos de estos asentamientos: sus tanques de agua. Erigidos en las cimas de torres construidas en los centros cívicos, con banderas nacionales y los nombres de los pueblos pintados en sus caras, su diseño incluyó el montaje de puestos de observación en altura para posibilitar la vigilancia de las casas y las áreas rurales que los rodeaban (Imagen № 2). Sus formas constructivas remitían a un imaginario de la guerra que, durante los meses de su edificación, quedó asentado en los relatos públicos que señalaban a los "mangrullos fortineros" como su fuente de inspiración. ${ }^{3}$ Al quedar asociados a los puestos de vigilancia de los fortines emplazados durante lo que los militares llamaban las "guerras contra el indio" (ocasión del exterminio de parte de la población indígena en nuestro país), la construcción de los tanques permitía a los uniformados trazar continuidades y paralelismos con la "guerra contra la subversión" que, según decían, estaban realizando en aquel presente. Este tipo de invocaciones permitían producir un 
escenario bélico legitimado en la continuidad de esas conflagraciones, entre las que también se incluían, por entonces, las equiparaciones con las "guerras independentistas" evocadas en el nombre del operativo desplegado en Tucumán.

Los tanques-mangrullos remitían, además, al espacio que podía ser observado desde ellos: el "monte" circundante a los pueblos, narrado por los militares como el lugar en el que se habían producido los "enfrentamientos" con los guerrilleros y, por ende, como el epicentro de la "guerra". El "monte" tucumano era representado en los discursos oficiales de aquellos tiempos como un espacio selvático en el que radicaba el peligro, el mal y el enemigo encarnado en la "subversión". A pesar de que la guerrilla rural había sido desarticulada antes de la inauguración de los pueblos (Vilas, 1977), la presencia de los tanques servía para recordar que la amenaza desde el "monte" persistía, reavivando un imaginario bélico en el que aquel espacio era su componente central. También se ayudaba de ese modo a justificar el control sobre la población reubicada como una de las formas de "prevenir" la "subversión" que -en la concepción castrense y conforme a lo sucedido previamente en la zona- podía abarcar tanto la lucha armada como los conflictos gremiales.

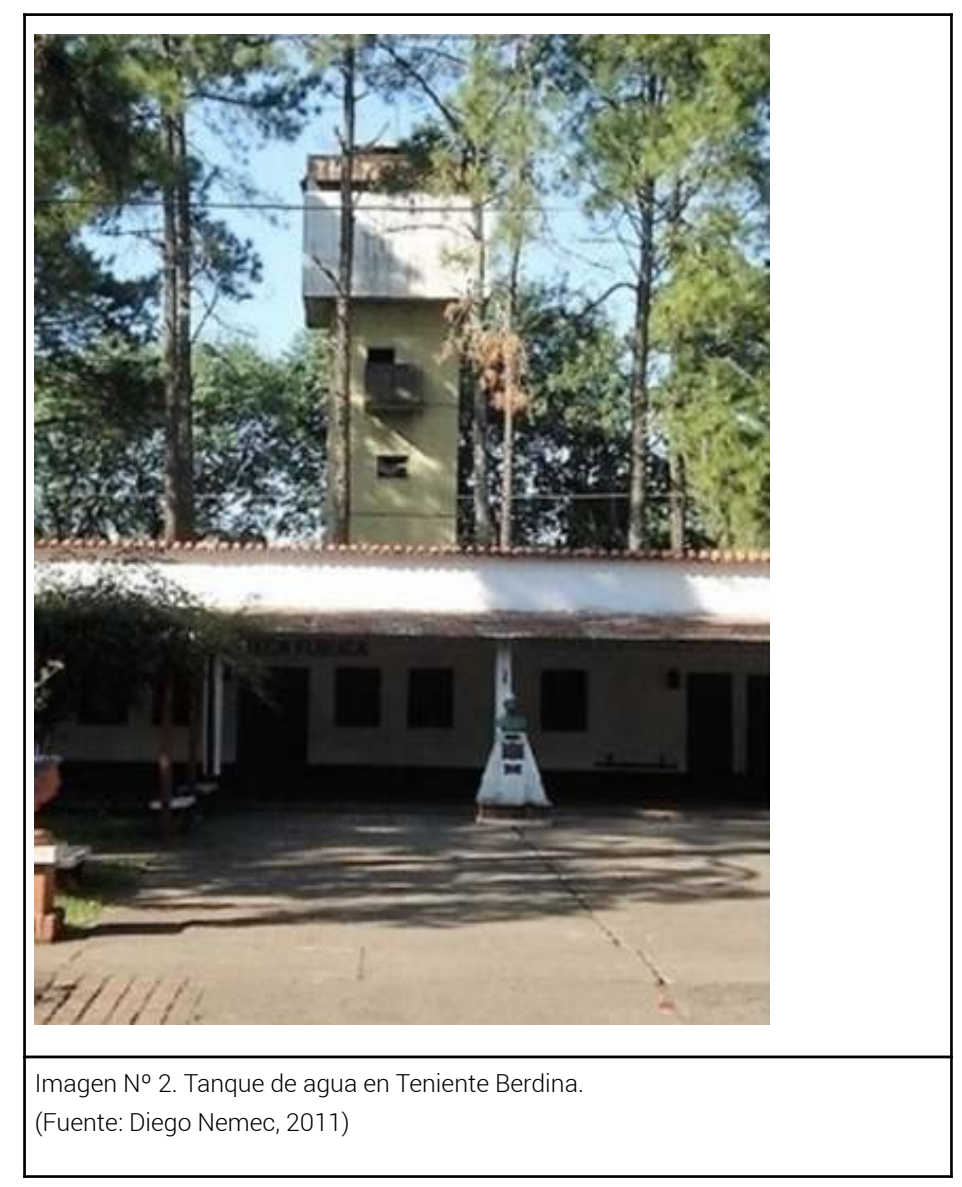

10 Durante los actos de fundación, jefes militares e integrantes del gobierno nacional que acompañaron a Bussi recibieron las armas supuestamente capturadas a los guerrilleros como si fueran un "trofeo de guerra". En los meses finales de 1976, los generales Jorge Rafael Videla, Luciano Benjamín Menéndez y Roberto Viola y el contraalmirante Julio Bardi las tomaron de la mano de jóvenes oficiales en operaciones, ofrendadas en nombre de los cuadros y la tropa del Operativo Independencia. ${ }^{4}$ Estas armas eran 
mostradas públicamente como la expresión material de la derrota del enemigo y su exhibición era parte de una gestualidad clásica de la guerra que permitía revelar el carácter heroico de los militares y la peligrosidad del adversario. Como ritual bélico, la exposición de estos "trofeos" ayudaba a producir una ceremonia de una "guerra" victoriosa, sobredimensionando los "combates" con la guerrilla y ocultando lo que sucedía en los centros clandestinos de detención.

11 Asimismo, el "monte" contiguo a Teniente Berdina fue el escenario, en noviembre del año siguiente, de uno de los dos "simulacros de combate" que el Ejército realizó en Tucumán para mostrar a la población la forma en la que -según su relato- se había derrotado a la "subversión". Disparos de cohetes desde un helicóptero, armas automáticas y morteros pesados fueron parte de esta teatralización que culminó con un desfile de los soldados en el pueblo y con las palabras del general Menéndez señalando que el "ejercicio" se había hecho en los lugares en donde los uniformados "se sacrificaban viviendo en campaña, para que no surja nunca más la delincuencia subversiva marxista". ${ }^{5} \mathrm{~A}$ la construcción del pueblo -con sus nombres militares, sus tanques o sus "trofeos"- ahora había que agregarle la producción de esta puesta en escena - difundida por la prensa provincial- destinada a magnificar los pocos "enfrentamientos" con guerrilleros producidos en los años previos y a representar la "lucha contra la subversión" a partir de imágenes clásicas de una guerra.

Los homenajes a los militares "caídos" en la primera etapa del Operativo Independencia fueron claves en esta construcción de un escenario bélico durante los años fundacionales de los cuatro asentamientos (Garaño, 2012). La voluntad conmemorativa de los uniformados quedó de manifiesto en los nombres elegidos para los pueblos, así como en los discursos, actos, carteles y bustos desplegados en ellos. Incluso, se puede apreciar en las identidades de los primeros niños allí nacidos, que fueron bautizados con los apellidos de los militares homenajeados incorporados a sus nombres de pila, integrándolos simbólicamente a la "familia militar" y haciendo perdurar la memoria de los "caídos" a través de la vida misma de sus nuevos habitantes.

13 Estos homenajes implicaron caracterizaciones de los "héroes" en las que se destacaba que sus muertes se habían producido en "combate", dejándose en claro el carácter valiente, patriótico y cristiano de todos ellos y, por contraposición, la ausencia de esos valores en el enemigo derrotado. Los uniformados "caídos" eran presentados, además, como el ejemplo del "sacrificio" que las Fuerzas Armadas estaban haciendo por la Patria. Esto quedó simbolizado en la exhibición del dolor de los familiares de los militares muertos que, al ser invitados a los actos de inauguración de los asentamientos, permitían recordar a los nuevos pobladores que el disciplinamiento requerido era parte del pago de una deuda con la "familia castrense" que se había sacrificado para que ellos pudieran vivir en "paz".

14 Algunas de estas caracterizaciones pueden ser observadas en un monumento inaugurado en 1980 en Teniente Berdina (Imagen № 3). Allí se reprodujeron las palabras de una carta que la madre del oficial homenajeado escribió tras la muerte de su hijo (Gayol y Kessler, 2012). En esta se condensaron, alrededor de la figura del "soldado caído", las representaciones del "héroe" que había defendido "a Dios, a la Patria y a la Familia" y la del irreparable dolor de su madre: una figuración potente, basada en el vínculo sanguíneo y afectivo, materializada en una placa y dispuesta en una esquina del pueblo para que sus pobladores y visitantes aprehendieran el sacrificio que habían realizado los uniformados en el sudoeste tucumano. 


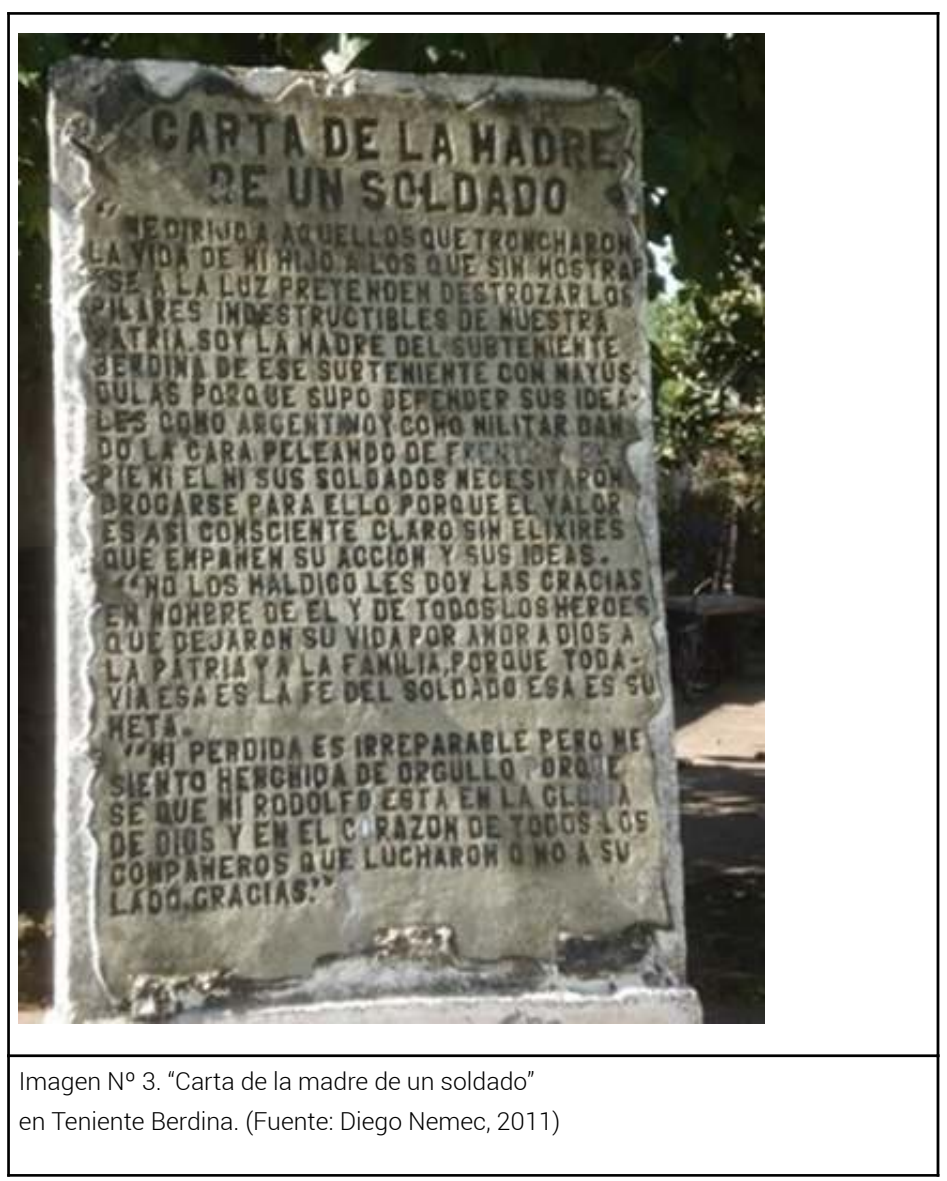

\section{Una memoria perdurable}

El uso de los pueblos como escenario y vidriera bélica estuvo destinado a un público privilegiado al que se debía controlar y convencer: los pobladores del sudoeste provincial, que experimentaron en carne propia las prácticas criminales aplicadas por el Ejército en esa zona, y los propios soldados conscriptos movilizados durante el operativo. Las estrategias de propaganda y justificación también apuntaron a un público provincial y nacional, algo que quedó de manifiesto en las visitas que el presidente Videla, jefes militares, ministros nacionales, periodistas, artistas, deportistas, curas, jueces, fiscales y gremialistas efectuaron a los pueblos, todos ellos invitados y acompañados por Bussi u otros jefes castrenses. Entre los personajes populares que arribaron a los asentamientos desde Buenos Aires estuvieron el boxeador Carlos Monzón, el cantante "Palito" Ortega y el periodista Mariano Grondona, quienes con su presencia ayudaron a difundir y legitimar la acción castrense en la zona. Se organizaron, además, reiteradas excursiones para estudiantes de distintos lugares de la provincia y para la población de la capital tucumana interesada en conocer los asentamientos. Los excursionistas fueron guiados por personal especializado, generalmente militar, lo que permitió al Ejército llevar a cabo tareas de "acción psicológica", apelando al uso de las marcas, prácticas y discursos descriptos en el apartado anterior. 

provincia: violenta y coercitiva y, al mismo tiempo, productiva de relaciones sociales, nuevas subjetividades y espacialidades. Al día de hoy los asentamientos siguen existiendo, conservando sus nombres y muchas de las marcas producidas por los militares. En ellos aún se puede escuchar -entre varios de sus pobladores- los discursos que se refieren a los setenta como la época de la "guerra" y de la "subversión". En los últimos años, algunos de estos poblados fueron el escenario de actos oficiales en los que ciertos participantes se refirieron al Operativo Independencia en clave bélica, en línea con los relatos difundidos por los uniformados en el pasado. Es posible que, a esta altura, esos discursos que circulan en aquellos lugares sean parte de su propia identidad y que hayan sido aceptados por varios de sus habitantes como parte de su historia.

cuestión no es un tema menor en una provincia en la que la aparición del bussismo como movimiento político democrático y el triunfo de Bussi como gobernador electo en 1995 expresó la persistencia, entre una importante porción de la población provincial, de una memoria social favorable al gobierno dictatorial que caracterizaba lo sucedido en los años setenta como una "guerra" (Crenzel, 2001): es decir, que adoptaba el marco explicativo usado por los uniformados para justificar el terrorismo de Estado. El estudio de las acciones castrenses realizadas en los pueblos quizás sea uno de los eslabones, entre muchos otros, que puedan ayudar a comprender estas permanencias durante los años democráticos en Tucumán.

\section{BIBLIOGRAPHY}

Colombo, P. (2016). L'urbanisation forcé comme politique contre-insurrectionnelle. La vie au sein des villages stratégiques construits en Argentine (1976-1978). Cultures \& Conflits, 103-104, 91-110.

Comisión Bicameral Investigadora de las Violaciones de los Derechos Humanos (1991). Informe de la Comisión Bicameral investigadora de las violaciones de los Derechos Humanos en la provincia de Tucumán (1974-1983). Madrid: IEPALA-UNT.

Crenzel, E. (2001). Memorias enfrentadas. El voto a Bussi en Tucumán. San Miguel de Tucumán: Facultad de Filosofía y Letras, Universidad Nacional de Tucumán.

Franco, M. (2012). Un enemigo para la nación: orden interno, violencia y «subversión», 1973-1976. Buenos Aires: Fondo de Cultura Económica.

Garaño, S. (2012). Entre el cuartel y el monte. Soldados, militantes y militares durante el Operativo Independencia (Tucumán, 1975-1977). Tesis doctoral no publicada. Facultad de Filosofía y Letras, Universidad Nacional de Buenos Aires.

Garaño, S. (2015). La construcción de los cuatro pueblos en el pedemonte tucumano. La apuesta productiva del Operativo Independencia (Tucumán, 1975-1977). Avances del CESOR, 12(12), 157-170.

Gayol, S. y Kessler, G. (2012). Tributo en la Argentina post-dictadura: los 'muertos por la subversión'. Sociohistórica. Cuadernos del CISH, 29, 157-182.

Corpus, Vol. 10, № .1 | 2020 
Gobierno de la Provincia de Tucumán. (1977). Tras la incertidumbre, una esperanza: Tucumán, Argentina. Cuna de la Independencia: 1816-1977. Sepulcro de la subversión: 1975-1977. San Miguel de Tucumán: Poder Ejecutivo de la Provincia de Tucumán.

Jelin, E. (2002). Los trabajos de la memoria. Madrid: Siglo Veintiuno Editores.

Nemec, D. (2019). Pueblos de la “guerra". Pueblos de la "paz". Los pueblos rurales del Operativo Independencia (Tucumán, 1976-1977). San Miguel de Tucumán: Editorial de la Universidad Nacional de Tucumán.

Pucci, R. (2009). Tucumán, 1975. La guerrilla y el terrorismo de Estado antes del golpe militar. En L. M. Bonano y R. Pucci (comps.), Autoritarismo y dictadura en Tucumán, (pp. 235-259). Buenos Aires: Editorial Catálogos.

Taire, M. (2008). El último grito. 1974: Crónica de la huelga de los obreros tucumanos de la FOTIA. Buenos Aires: Lumiere.

Vilas, A. E. (1977). Manuscrito sobre el Operativo Independencia (copia de la que está en el archivo del CELS). Manuscrito no publicado.

\section{Fuentes}

La Gaceta (25/09/1976). "Llámese Subteniente Berdina el pueblo erigido en Caspinchango". San Miguel de Tucumán.

La Gaceta (20/11/1976). "El Jefe del Estado Mayor General del Ejército, General Roberto Viola, en la zona de operaciones antisubversivas". San Miguel de Tucumán.

La Gaceta (19/12/1976). "Fundación de un nuevo pueblo: 'Sargento Moya'". San Miguel de Tucumán.

La Gaceta (19/08/1977). "Inaugurará hoy el gobierno el nuevo pueblo 'Soldado Maldonado'". San Miguel de Tucumán.

La Gaceta (24/09/1977). "Se inaugurará esta tarde el Pueblo Capitán Cáceres". San Miguel de Tucumán.

La Gaceta (11/11/1977). "El General Menéndez observó en Berdina un ejercicio militar de tipo antisubversivo". San Miguel de Tucumán.

\section{NOTES}

1. Las comillas dobles en este texto dan cuenta -salvo escasas excepciones- de las categorías nativas utilizadas por el personal militar para nombrar, describir o explicar los diferentes aspectos de la represión que estaban llevando a cabo durante aquellos años en Tucumán.

2. Debido al formato y brevedad de este debate, el lector interesado en ampliar su conocimiento sobre estos pueblos puede remitirse a otros trabajos de nuestra autoría (Garaño, 2015; Nemec, 2019) y a un artículo de Colombo (2016).

3. La Gaceta, $19 / 8 / 1977$ y $24 / 9 / 1977$.

4. La Gaceta 25/9/1976, 20/11/1976 y 19/12/1976.

5. La Gaceta, 11/11/1977. Op cit 


\section{AUTHORS}

\section{DIEGO NEMEC}

Universidad Nacional Arturo Jauretche, Universidad Nacional de San Martín, Argentina

Correo electrónico: diegonemec@gmail.com

\section{SANTIAGO GARAÑO}

Universidad Nacional de Lanús, Universidad Nacional de Tres de Febrero, y Consejo Nacional de Investigaciones Científicas y Técnicas, Argentina.

Correo electrónico: sgarano@hotmail.com 